\title{
Curadoria: deslocamentos, impasses, possibilidades
}

Marisa Flórido Cesar*

RESUMO: Os anos sessenta e setenta testemunharam a ascensão de um personagem no sistema das artes, e a redefinição de sua função, lugar e poder: o curador. Sua ascensão é simultânea à expansão do campo de atuação e reflexão da arte, ao declínio da figura paradigmática do crítico de arte, e ao aumento considerável no número e na diversidade de exposições das últimas décadas. O texto trata das relações entre crítica e curadoria, dos deslocamentos, indefinições e contaminações que se operaram desde então, dos atuais impasses e possibilidades.

PALAVRAS-CHAVE: crítica de arte, curadoria, arte contemporânea.

ABSTRACT: The sixties and seventies have witnessed the rise of a character in the art system, as well as the redefinition of his role, position and power: the curator. This rise is simultaneous to the expansion field of action and reflection of art, the decline of paradigmatic figure of the art critic and the considerable increase in the number and diversity of exhibitions in recent decades. The text deals with the relationship between criticism and curatorship as well as displacement, uncertainties and contamination that have taken place since its origin, the current impasses and possibilities of curatorial practice.

KEYWORDS: art criticism, curatorship, contemporary art

\footnotetext{
* Marisa Flórido Cesar é Professora adjunto do Instituto de Artes da Universidade do Estado do Rio de Janeiro, crítica de arte e curadora independente. Doutora pelo Programa de Pós-Graduação em Artes Visuais pela Escola de Belas-Artes da Universidade Federal do Rio de Janeiro, na área de concentração de história e crítica de arte.
} 
"Não poder voltar à época em que nenhum vocábulo paralisava os seres, ao laconismo da interjeição, ao paraíso do embotamento, ao estupor alegre anterior aos idiomas...!" 1

Emil Cioran

Há muito as palavras não conseguem enunciar sem explicitar ambiguidades de fundo, como se incapazes de designar sem deixar de expor, na impossibilidade de uma transmissão completa, estilhaços e mudez. Perdemos a crença em um laço, na origem, que encerraria uma articulação inequívoca entre ver e falar, que nos prometia uma tradução perfeita dos signos, uma interpretação precisa das experiências de nossa existência neste mundo. Estamos condenados a vagar nos delírios das exegeses, das interpretações que não nos liberam da arbitrariedade que ata o signo àquilo que ele significa? Que não nos garantem a autenticidade dos discursos? Mas tais interrogações já não possuem respostas que não estejam atravessadas de incoerências, paradoxos, elipses.

Vejamos duas palavras: crise e crítica. Ambas possuem a raiz "kr-", ambas vêm do verbo grego Kríno: separar, escolher, discernir, julgar. Quando a palavra "crítica" surge no vocabulário da filosofia ocidental (lembremo-nos de Kant e sua crítica do juízo), 'crítica' significa, sobretudo, questionamento da razão sobre seus limites, ou, como diz Giorgio Agamben no prefácio de Estâncias/ a palavra e o fantasma na cultura ocidental², significa investigação sobre os limites do conhecimento, sobre aquilo que não é possível colocar nem apreender.

Sabemos que a consolidação da crítica de arte, há mais de dois séculos, na figura de um especialista como intermediador entre arte e público, vincula-se pelo menos a duas ocorrências principais: a primeira, mais evidente, à ampliação do público de arte pela transferência do mecenato da arte da Aristocracia e da Igreja para a burguesia. A segunda, à especialização das esferas do conhecimento, da ação e da sensibilidade (ou seja, as esferas cognitiva, ético-política e estética) que, fechando-se em campos autônomos, buscariam respostas que lhes fossem próprias, construindo grandes narrativas críticas a legitimar sua autonomia.

Apesar dessa separação, a crítica de arte se consolida com escritores e poetas, como Diderot e Baudelaire. O que nos aponta essa aparente incongruência? Ora, a cisão entre sentir e 
pensar, ou antes, entre "palavra poética e palavra pensante", como diz Agamben, está enraizada em tradição ocidental, basta pensarmos na expulsão do poeta da República por Platão. Na modernidade, entretanto, essa cisão radicaliza-se. A palavra poética, "palavra inconsciente", como fala Agamben, "goza do objeto sem conhecê-lo porque o representa na forma; a palavra filosófica, palavra consciente, conhece mas não goza do objeto porque não consegue representá-lo". E a crítica "nasce no momento em que essa cisão alcança o seu ponto extremo. Ela situa-se no deslocamento da palavra ocidental e sinaliza (..) um estatuto unitário do dizer. (...) Ela não representa nem conhece, mas conhece a representação" ${ }^{3}$. "À apropriação sem consciência (arte) e à consciência sem gozo (pensamento), a crítica contrapõe o gozo daquilo que não pode ser possuído e a posse daquilo que não pode ser gozado. O que fica fechado na estância da crítica é nada, mas esse nada contém a inapreensibilidade como o seu bem mais precioso". É desse modo que Agamben defende o pensamento crítico como um exercício que responde à impossível tarefa de se apropriar daquilo que ainda assim continua inapreensível.

Mas, apesar da histórica cisão entre pensamento e sensibilidade, razão e afeto, ação e contemplação, toda obra de arte que mereça tal denominação é também um ato do pensamento, assim como toda reflexão crítica que se digne como tal está atravessada de júbilo e potência poéticos. Do mesmo modo, toda atividade comporta uma posição de espectador (do mundo, da arte) e toda posição de espectador é também ativa, pois mais que intérprete é um coautor que desvia de modo imprevisto os sentidos das obras. Em seus ensaios críticos sobre o fantasma e a palavra, Agamben conclui belamente: "toda autêntica intenção poética ou artística se volta para o conhecimento, assim como todo verdadeiro filosofar está voltado para a alegria".

Poderíamos conjecturar a crítica de arte como o exercício de um pensamento que se vê, sem cessar, confrontado com seus próprios limites, com sua impotência. Como uma resposta sempre incompleta e hesitante - a esse incessante colocar em crise, pela arte, o pensamento e a sensibilidade. Não é a emissão de um juízo depreciativo, como alardeia o senso comum. $O$ encontro com a "obra de arte" (denominação cada vez mais insuficiente) é o contato com uma alteridade, com um ponto cego. A crítica é uma reflexão imprecisa, insuficiente e um tanto arbitrária sobre o que se vê, pensa e sente. 
Se certa tradição da crítica de arte, nessa especialização moderna, construiria sua narrativa definindo uma "verdade" da arte ("um estatuto unitário do dizer", diria Agamben), ela o fez - entendamos com um pouco mais de complexidade - ao mesmo tempo em que lançava o pensamento sobre o que permanecia obstinadamente impreciso. Por isso certas concepções formalistas da arte viveriam nos anos sessenta uma contradição irreconciliável: pois cada categoria artística se definia a priori a partir de sua especificidade, ao mesmo tempo argumentando que se formulava a partir da investigação crítica de sua natureza enquanto arte, interrogando-se e respondendo-se: - O que é arte? Arte.

Por suas inconsistências internas, pelo esgotamento das narrativas históricas ou dos discursos teóricos, os anos sessenta seriam prósperos pela diversidade da produção artística. A Pop, a Minimal, a Arte conceitual, o Fluxus, o neoconcretismo no Brasil, as instalações, os trabalhos em site-specific ou in situ, a Land Art, entre outras manifestações, já não identificam uma verdade da arte, sequer distinguem qualquer verdade. Como os idiomas distintos que se formam após o fracasso da Torre de Babel, nenhuma tradução pode se asseverar como legítima, nem esse "algo" tem limites ou constitui-se precisamente, nenhum signo possui apenas uma interpretação, nenhuma palavra se esgota em uma única designação, nenhum silêncio garante sua transparência.

A arte, desalojada desses discursos, perderia o privilégio de qualquer unidade residual em sua produção ou o conforto de uma distinção evidente: ou todos os meios são aceitáveis, ou nada pode mais se constituir, nem a própria arte. Invadindo-se pelas exterioridades, deslocando-se para os lugares do mundo e para as contradições da vida, introjetando o tempo, atravessando-se pela palavra escrita e falada, a arte exploraria suas ambiguidades e perversões - ampliaria sua própria questão, refletiria sua existência e a do mundo, encararia seus conflitos, sua ausências, suas impossibilidades.

Nesse período, não se esgotariam os anúncios das dissoluções e mortes na arte. Uma fratura não apenas em relação aos postulados formalistas do modernismo como também à própria História da arte. Se as teorias pós-estruturalistas questionariam a autoria e as categorias formais, teóricos como Hans Belting e Arthur Danto denominariam aquele momento de "pós-histórico", uma vez que o fim das grandes narrativas (que legitimavam a arte na História, na 
afirmação de uma "verdade visual") fez desaparecer a consciência fechada e unívoca que a arte tinha sobre si mesma. A arte, sem uma determinação precisa de si mesma, poderia ser qualquer coisa ou não ser. A própria historiografia da arte confrontava-se com seus limites e esgotamentos, era necessário abrir seu campo a outros saberes e experiências, inclusive a outras temporalidades além da linear e teleológica que determinou o projeto moderno.

Uma ciranda de nomeações se instauraria então: "criação," palavra do vocabulário artístico, pareceria banida. "Produção, confecção, fabricação, ação", entre outras, às vezes, a substituíram. O termo "obra de arte", por sua alusão a um objeto finalizado e autônomo, eventualmente se transformaria em "trabalho," "situação," " acontecimento", "produto," "processo," etc. O "espectador" em "participante" ou "coautor" da ação. Sobreviveria estranhamente, nessa ciranda de esquecimentos, a palavra "artista". Nem por isso a definição de seu estatuto é menos problemática: o que é um artista? Estamos longe do tradutor de desígnios, do gênio divino ou inato, do demiurgo e sua missão de revelar arte e mundo. Não recuperamos, todavia, o artesão grego ou aquele do medievo. A denominação "trabalho de arte" também não nos devolve à mera fabricação de objetos, à habilidade manual sem um saber teórico. Afinal, a "criação artística" que teve como modelo a criação cristã - aparição do nada -, ou a criação grega "matéria como substrato passivo atualizado por uma forma, segundo Aristóteles" ${ }^{4}$-, como percebeu Gilles Thiberghian, soaria cada vez mais como uma quimera. O artista, esse sobrevivente das "de-nominações" artísticas, era exposto muitas vezes como uma ilusão nostálgica.

Sistemas a priori discursivos, perceptivos, culturais, ideológicos, políticos, quaisquer que fossem, são explicitados. A excursão dos artistas para fora dos meios artísticos e dos locais convencionais de exposição teve como efeito perscrutar o campo nos quais se inscreviam e os dados culturais pelos quais se dava essa inscrição. Dados que estavam hibernados na autorreferência da obra de arte e na neutralidade exigida a seu lugar de apresentação, como o célebre cubo branco.

A obra autônoma resplandecendo em si mesma para além de qualquer condição da experiência, nas coordenadas abstratas e ideais do espaço e do tempo — onde o cubo branco é a figura paradigmática - , soaria cada vez mais improvável. Não porque as obras que reivindicam sua autorreferência desapareceram, mas porque os discursos que as legitimavam já não encontram onde ancorar suas verdades. 
O cubo branco, receptáculo indiferenciado cuja arquitetura deveria preservar a neutralidade máxima para que apenas a obra de arte tivesse existência e se revelasse, se mostraria cada vez mais como "uma ilusão ideológica". O famoso cubo branco sempre esteve impregnado da ideologia que o concebeu e a qual deveria velar: os valores que legitimavam e garantiam um juízo seguro para a arte.

O que ficava evidente então é que toda obra está referida e é relativa a uma rede de relações que a ultrapassa: a uma trama de afetos, fenômenos, concepções e poderes exteriores, inclusive ao conjunto de valores para a qual se dirige, à vizinhança ao lado da qual ela se coloca, às singularidades daquele para quem ela se endereça. Os diversos modos de aparição das obras considerariam, nessas relações, o que, como, de que lugar, com que meios, com que gama de valores, as obras se inserem e se engendram. Lição de Duchamp: está-se sempre no interior de alguma circunstância. E uma vez que essas circunstâncias mudam, a percepção da obra também se dá em relação a cada situação, infinitos sentidos surgirão e desaparecerão nesse movimento: toda obra está a um só tempo situada e deslocada, são suas geografias circunstanciais.

Em resumo, a distinção entre objeto e prática, produção e recepção, conduziria a algumas dissipações e deslocamentos: a fluidez de fronteiras, o comércio entre as categorias artísticas, entre vários saberes e campos da experiência; entre a obra, o artista e o espectador; entre a arte e o mundo. Uma imprecisão que tanto expandiria o campo de atuação e reflexão da arte, quanto colocaria a própria arte nos limites de sua indefinição. O crítico não escaparia dessas incertezas. As trepidações e expansões na prática e na reflexão artísticas, a desconfiança na neutralidade expositiva e no solipsismo da arte, o esgotamento das metanarrativas de legitimação da arte, tanto arrastariam a figura do crítico nesses sismos, como permitiriam a emergência de um novo papel e função no sistema das artes: o curador.

Podemos apontar algumas exposições que marcam essa transição: Information, de Kynaston McShine, no MoMA, uma apresentação experimental de arte conceitual e arte processual em 1970; When Attitudes Become Form de Harald Szeemann, geralmente visto como um dos primeiros curadores independentes, ao ver-se obrigado a sair da Kunsthalle de Berna, em 1969, por conta da reação polêmica na cidade (a exposição reuniu uma geração de artistas com 
práticas afins como arte processual, arte povera e similares). Na Documenta 5, Questions of Reality: The Image-World Today, em 1972, também organizada por Harald Szeemann, a tensão se explicitaria justamente com os artistas. Naquela Documenta, Szeemann não apenas reuniu obras de arte, mas as confrontou com o campo da cultura (expondo ao lado de imagens de ficção científica, por exemplo) por meio de três recortes temáticos, entre os quais "Mitologias Individuais".

Curiosa contradição se colocaria desde ali: muitas das práticas artísticas dos anos 60 e 70 guardariam em comum a diversidade de linguagem, a expansão da arte para além de suas categorias específicas e de sua autorreferência, a desconfiança nas noções de autoria e de originalidade como valor de verdade, e o questionamento da arte como expressão do Eu privado. "Mitologias Individuais" trazia mais de 70 artistas trabalhando com performance, instalação e arte processual. Para Szeemann, toda ação artística relacionava-se à formação de uma mitologia interior, o que causou reação dos artistas que buscavam se opor à mítica do artista, à sua interioridade ou à expressão manifesta no objeto artístico. Ao mesmo tempo, os artistas se ressentiriam dessa apropriação autoral realizada pelo curador. Daniel Buren, por exemplo, (expondo em outra seção), o acusaria de não expor obras, mas expor a exposição, não respeitando a especificidade e autonomia das práticas artísticas e encapsulando a autoria dos artistas sob uma ideia curatorial em que o curador se torna um autor (surgia no horizonte da arte a "mitologia individual" do curador).

No mesmo período, de modo similar, Frederico de Moraes organizava o evento Do Corpo à Terra em abril de 1970, no Parque Municipal de Belo Horizonte, em Minas Gerais. Moraes afirmava que os trabalhos de arte não poderiam mais ser realizados para contemplação, eram antes proposições em que o artista deixava de ser um autor de obras para ser um propositor de situações ou um apropriador de objetos ou eventos. Numa espécie de "contra-história", "a arte de guerrilha", tal como definida por ele, postulava a ruptura com a arte de museus e salões, a confrontação aos contextos político-sociais (estávamos em plena ditadura militar), a execução da obra no local de sua apresentação, a exposição da arte em locais alternativos, a ocorrência de vários trabalhos (como happenings e instalações efêmeras) simultaneamente em locais diferentes, e o questionamento do objeto como categoria artística, da estrutura formal e do uso de materiais nobres. Em seu texto Contra a arte afluente, ele questionaria o lugar 
e a função delimitada e específica de cada participante do campo artístico, em evidência, o do próprio crítico: "não há mais obra. Não é mais possível qualquer julgamento. O crítico é hoje um profissional inútil. Sobra talvez o teórico." Por isso, para Moraes, era urgente doravante que se fizesse uma crítica aberta e criadora: "o artista, o público e o crítico mudam continuamente suas posições no acontecimento e o próprio artista pode ser vítima da emboscada tramada pelo espectador" 5 .

Talvez, mais fundamental do que discutir a pertinência e/ou os limites da autoria artística e curatorial, seja compreender os deslocamentos e indeterminações que jazem sob esses novos personagens e papéis no sistema da arte, e quais suas contradições mais evidentes.

\section{A articulação entre as formas visuais e as palavras que as colocam em relação}

Ao ficar evidenciado que qualquer paradigma ou verdade sobre a arte era insustentável, o crítico não poderia mais assumir o lugar de um especialista determinando os destinos históricos da arte e codificando regras do seu exterior, a análise crítica necessitaria abdicar de modelos apriorísticos para confrontar uma miríade de tramas complexas, sobrepostas ou interligadas, tão estranhas quanto imprevisíveis e obscuras. Talvez como uma espécie de escrita que se propõe a não mais enunciar grandes verdades para a arte, mas, quando muito, pequenas hipóteses sobre os sentidos de algo que continua inapreensível. Uma escrita na qual as incoerências e as arbitrariedades não se resolvem e vêm nela ter lugar. É ficção, não no sentido de um logro, de uma falsidade, mas como experimentação do pensamento sempre aberta e incompleta. É então que se projeta a figura do curador em contrapartida ao declínio da autoridade carismática do crítico. No lugar do legislador, daquele que determina a priori os destinos da arte, entra em cena, supostamente, o propositor de hipóteses infinitas de exposição.

O curador é aquele que, no momento em que a arte é descontextualizada das grandes narrativas que a legitimavam em verdade, toma a obra e a inscreve em uma determinada situação expositiva. Mas isso foi precedido pela própria prática artística e não o contrário. Ou seja, foram as inúmeras experimentações artísticas que deslocaram a ênfase na obra ensimesmada e autossuficiente para seu caráter relativo e para as relações que estabelece além de si. Por isso, qualquer recorte curatorial é fruto de uma escolha que não exclui o caráter arbitrário 
dessa seleção. É quando muito a apresentação de certa situação, a ocasião para que se dêem alguns encontros e algumas relações (entre obras, artistas, espectadores, ocasiões, contextos etc.). Parafraseando Duchamp, que afirmou que a arte é a "figuração de um possível", um recorte curatorial é a apresentação de um possível. Uma possibilidade entre muitas.

No lugar de grandes verdades, o curador pretende criar molduras de inscrição efêmera para a obra, lançar em sua direção pequenas hipóteses de aproximação e acesso. Abre campos provisórios de significação. Pois temos, doravante, que conviver com o fato de que uma obra está perpassada de silêncios como produz uma miríade de pequenas narrativas e outros sentidos dos quais não temos o acesso absoluto, a chave de uma decifração completa. A obra de arte encerra e exibe seu hermetismo.

Algumas vezes, a curadoria se coloca como uma proposição ensaística ou uma reflexão que abraça obras diversas, inscrevendo-as sob um mesmo tópico temático, histórico, geracional ou geográfico. Em outras, o curador é um propositor de atuações ou experimentações, em que os artistas têm de elaborar projetos e realizar trabalhos específicos. Muitas vezes, tem a sensibilidade de perceber manifestações artísticas muito próximas que, se desconhecendo, começam a surgir em locais distintos, mas que sintomatizam urgências comuns. Ou então, com o propósito de realizar uma revisão da história da arte, reapresenta as obras do passado, fazendo emergir os sentidos recalcados pelos grandes discursos ou por uma suposta neutralidade da montagem e do lugar de exposição. Ele assume, desse modo, o compromisso de desestabilizar as leituras autorizadas, projetando sobre a obra, novas abordagens, outras vizinhanças.

Se o curador é aquele que, no momento em que a arte é descontextualizada das grandes narrativas, toma a obra e a inscreve em uma determinada situação expositiva, poderíamos dizer que há, portanto, um deslocamento do poder da palavra monopolizada para a situação expositiva, ou seja, para visibilidade, para a imagem. Mas isso decorre também de uma mudança no regime de conexão entre as formas visuais e as palavras que as colocam em relação. Há um colapso e um rearranjo entre imagens e relatos, entre o "expor e o significar." O que não significa que a arte não demande cada vez mais a escrita crítica, mas que ela está também passando por intensas transformações: explodem cursos e pós-graduações de arte, escreve-se sobre arte em blogs, sites, revistas especializadas, catálogos, periódicos... 
Tal fenômeno não se restringe às artes visuais, basta pensarmos no impacto das tecnologias, da montagem do cinema à internet e a profusão de dispositivos portáteis de captação e difusão de imagens (como câmaras e celulares), geradoras tanto de outras temporalidades, como de fragmentação das narrativas, ou de choque entre estas e as imagens, e de novas articulações entre o visível e o dizível. Não por acaso, alguns vão associar a prática curatorial à direção de um filme, ou a própria escrita da história da arte à montagem. Podemos deduzir inclusive porque a obra de Aby Warburg vem sendo resgatada e tão estudada: seu Atlas Mnemosyne e a transdisciplinaridade de sua "ciência sem nome" colocam questões e reflexões bastante pertinentes à atualidade. E de modo próximo a Warburg, Walter Benjamin, que, avesso ao historicismo linear, articulava o pensamento por imagens e constelações (ambos referências importantes a teóricos como Georges Didi-Huberman.).

Benjamin dizia que "o escrito é como uma cidade, para a qual as palavras são mil portas". É preciso escrever por trovões, por fulgurações. Por isso o pensamento nele se articula menos por conceitos, e mais por imagens, como acesso a outras formas de conhecimento. Benjamin sequestrava a imagem de seu contexto, da clausura do encadeamento temporal da história linear, para, como uma mônada, dar o salto no insólito. Por isso o presente não seria para ele algo entre um passado ou um futuro que the dá sentido, mas um lampejo, uma intensidade desencadeadora de outras reminiscências, de novos saberes. A montagem (literária ou cinematográfica) que ele lançava, deslocava conteúdos temporais e espaciais cristalizados como verdades. Implodia-se a forma do passado em elementos fragmentários, constelações em mobilidade em que o passado se junta como um relâmpago ao agora. Era preciso deslocar o saber para revelar a potencialidade do que é incompleto, as alegorias como conexões arbitrárias, a escrita como estilhaços de uma língua original em queda, cheia de possibilidades e redenções.

Estas são as questões colocadas frente ao colapso e às rearticulações entre imagens, entre imagens e relatos, entre o expor e o significar: é possível pensar por imagens? É possível converter o pathos emocional relacionado à imagem ao logos dos conceitos e das palavras? A resposta sem-resposta talvez esteja na escuta da frase de Giordano Bruno que teima em ecoar pelos séculos: "Pensar é especular com imagens». 


\section{Do museu histórico à exposição global e ao marketing cultural}

Como já dito, a emergência da figura do curador tem relação com a crise de uma narrativa dominante nas artes e do papel centralizador do crítico. Vinculada a esse deslocamento, estava a desconfiança na neutralidade do espaço expositivo. Na medida em que se diversificam as práticas artísticas, em que estas se deslocam para se inserir em campos discursivos, institucionais, culturais e sociais muito mais amplos, desafios são colocados também à curadoria e ao pensamento. Mas as experiências curatoriais não podem se desvincular da reflexão teórica rigorosa, ou seja, da exigência de um pensamento que se expõe tanto na escrita como na visualidade. Essa proposição infinita de pequenas hipóteses de exposição, em que o curador torna-se muitas vezes uma espécie de mediador social (papel que se estende aos artistas) é, simultaneamente, cheia de possibilidades e esquizofrenias. É tanto radical como conservadora, iconoclasta como cooptável, como, aliás, é a arte contemporânea e tudo o mais no mundo atual.

Nathalie Heinich e Michael Pollak levantam algumas hipóteses sobre a transformação das funções de um curador. Se outrora, sua competência resumia-se a "assegurar a herança, enriquecer coleções, pesquisar e exibir", nas gerações que se seguiram, sua figura despersonalizada ganharia um status único e singular, assim como sua função se expandiria e passaria a mediar a exibição de obras para um público cada vez maior. A consolidação da profissão do curador como "autor de exposições" relaciona-se também, segundo os autores, a este fato: ao boom das exposições que ocorreu nas últimas décadas ao aumento no número de exposições em museus e instituições culturais, à diversificação das exposições (de assuntos e objetos mais diversos, como história natural, a feiras de arte). Uma expansão que demandaria novas funções e outros colaboradores, como o arquiteto responsável pela expografia, ou as equipes de confecção dos catálogos. Como outros, para Heinich e Pollak, o papel singular do curador se assemelha ao diretor de cinema: ambos se inserem na economia de produtos culturais destinados à massa de espectadores/consumidores; ambos demandam e coordenam uma equipe de profissionais. ${ }^{6}$

Ou seja, acrescentaríamos, o curador consolida seu status e profissionalização também pela hiperinflação das exposições de arte e na expansão do marketing cultural a elas associados. Cada vez mais circulariam os signos, as obras, os artistas, os curadores, as exposições, as 
hipóteses e os sentidos. Circulam as imagens e as informações pelas redes eletrônicas, circulam as mercadorias e os fluxos do capital global. E "o mercado global é uma comunidade em total interioridade, mas cujo interior é vazio ou anônimo" 7, como dirá Jean-Luc Nancy.

Deparamo-nos, portanto, com os impasses da arte: preservar-se do mercado das visibilidades (no qual a arte é moeda de troca do marketing cultural); interrogar e demandar sentidos sobre o que não é possível apreender. O curador, ao ter o poder de introduzir artistas e obras na circulação expositiva, de inseri-los no mundo da visibilidade (espetacular e midiática) da arte, abandona sua posição de propositor ocasional para reassumir o papel de legitimador. Um legitimador que não autoriza mais a verdade única da arte, mas a inserção do artista na exposição global. Todavia, o que supõe ter visibilidade hoje? O que supõe dar visibilidade? E que tipo de visibilidade a arte empresta? E não importa se dá visibilidade a um artista, a um governo, a uma empresa privada, ou a um movimento social. Inserido na economia global de mercado, o Brasil, como o restante do mundo ocidental, assiste à midiatização de sua vida social. A arte arrisca-se a ser signo manipulável de prestígio e marketing. Algo como o signo de uma publicidade, como signo-mercadoria. A própria exibição, sua "publicação" pervertida na publicidade do consumo, torna-se mercadoria, torna-se fetiche.

Como viver entre a confiança do espectador e a onipotência daquele que exibe? É uma relação, que não nos cabe aqui analisar dada sua complexidade, que articula ver e crer, exibir e existir, desejo e poder, e que faz a pulsão escópica do Ocidente, a pulsão de ver, confundir-se cada vez mais com a pulsão de exibir. É a partilha do indeterminado, a partilha do visível, se convertendo cada vez mais naquilo que Marie-José Mondzain chama de "mercado das visibilidades".

Em relações de resistência e inelutável conivência, a arte responde de modo diverso a seus impasses. E não apenas porque ela alimenta o marketing cultural (e dele também se sustenta), conferindo visibilidade a empresas, governos ou causas sociais. Mas porque as potências (como o mercado e as religiões, o espetáculo e a mídia) não são exteriores, moldam a vida e as subjetividades, investem naquilo que nomeamos "arte" de modo intrínseco. A resistência da arte (e de seus agentes como artistas, críticos ou curadores) é, portanto, também uma resistência a si mesma e uma resistência ao que somos. São guerras e querelas consigo 
mesma, eis o paradoxo. Entretanto, de certa forma, é nessa contradição que a arte parece hoje sustentar o seu mais fecundo exercício. Ou seja, na tensão entre o anseio de não se deixar instrumentalizar e sua inevitável dependência aos sistemas, poderes, afetos, que circulam entre nós.

Essas indagações não obterão jamais respostas fáceis e desprovidas de dúvidas. É como se cada gesto carregasse seus crepúsculos a exigir um cuidado redobrado, uma atenção incansável. $E$, enquanto o pensamento penetra suas nuvens e confronta sua esquiva, cabe-nos interrogar, sem trégua, nossa responsabilidade (aqui inseridos crítico, curadores, artistas) nestes processos.

\section{Notas}

1 CIORAN, Emil. A atrofia do verbo. In: Silogismos da Amargura. Tradução de José Thomaz Brum. Porto Alegre: Rocco, 1991, p.14.

2 AGAMBEN, Giorgio. Estâncias/ a palavra e o fantasma na cultura ocidental. Tradução de Selvino José Assmann. Belo Horizonte: Editora UFMG, 2007.

3 Idem ibidem, p. 13. (Agamben cita, como exemplo dessa cisão e das tentativas de transgredi-la, o grupo de lena, que propunha uma crítica que incluísse a própria negação, como exercício de negatividade e cujo conteúdo fosse o que nela não se encontrava).

4 TIBERGHIAN, Gilles A. A arte da Natureza. In: In: Arte \& Ensaios, Revista do Programa de Pós-Graduação em Artes Visuais EBA/ UFRJ, Rio de Janeiro: ano VII, n. 7, p. 171, 2000.

5 MORAES, Frederico de. O corpo é o motor da obra, 1970. [Publicado originalmente com o título "Contra a arte afluente" pela revista Vozes, janeiro-fevereiro - 1970. In: Artes plásticas, a crise da hora atual. Rio de janeiro, Paz e Terra, 1975, p24-34. Disponível em: http:// arteref.com/gente-de-arte/o-corpo-e-o-motor-da-obra/

6 HEINICH, Nathalie; POLLACK, Michael. Du conservateur de musée à l'auteur d'expositions: I'invention d'une position singulière. In: Sociologie du travail, vol. 31, $n^{\circ} 1$, pp. 29-49, 1989.

7 NANCY, Jean-Luc. Jean-Luc Nancy / Chantal Pontbriand, uma conversa. In: Arte \& Ensaios, Revista do Programa de Pós-Graduação em Artes Visuais EBA/UFRJ, Rio de Janeiro: ano VIII, n. 8, 2001.

\section{Referências}

AGAMBEN, Giorgio. Estâncias/a palavra e o fantasma na cultura ocidental. Tradução de Selvino José Assmann. Belo Horizonte: Editora UFMG, 2007.

CIORAN, Emil. A atrofia do verbo. In: Silogismos da Amargura. Tradução de José Thomaz Brum. Porto Alegre: Rocco, 1991. 
HEINICH, Nathalie; POLLACK, Michael. Du conservateur de musée à l'auteur d'expositions: I'invention d'une position singulière. In: Sociologie du travail, vol. 31, n 1, 1989.

NANCY, Jean-Luc. Jean-Luc Nancy / Chantal Pontbriand, uma conversa. In: Arte \& Ensaios, Revista do Programa de Pós-Graduação em Artes Visuais EBA/UFRJ, Rio de Janeiro: ano VIII, n. 8, 2001.

TIBERGHIAN, Gilles A. A arte da Natureza. In: Arte \& Ensaios, Revista do Programa de Pós-Graduação em Artes Visuais EBA/UFRJ, Rio de Janeiro: ano VII n. 7, 2000. 